Original Research Article

\title{
Knowledge, attitude and practice towards adverse drug reactions reporting in post graduate students of a tertiary care hospital
}

\author{
Aparna S. Chincholkar, Alisha Naik*
}

Department of Pharmacology, MIMER Medical College, Talegaon-Dabhade, Pune, Maharashtra, India

Received: 29 March 2019

Revised: 03 April 2019

Accepted: 03 May 2019

*Correspondence to:

Dr. Alisha Naik,

Email:

alishanaik1991@gmail.com

Copyright: () the author(s), publisher and licensee Medip Academy. This is an openaccess article distributed under the terms of the Creative Commons Attribution NonCommercial License, which permits unrestricted noncommercial use, distribution, and reproduction in any medium, provided the original work is properly cited.

\begin{abstract}
Background: Adverse Drug Reactions (ADRs) are a major cause of morbidity and mortality. Under reporting of ADRs by health care professionals is a very common problem worldwide. So, the present study was planned to assess the knowledge, attitude and practices of postgraduate (PG) students towards ADR reporting and suggest possible ways for improvement.

Methods: It was a cross sectional questionnaire-based study conducted among 44 PG students using a questionnaire with questions on knowledge (21), attitude (13) and practices (15) of ADR reporting. The questionnaire was analyzed question wise and the percentage was calculated using Microsoft Excel spreadsheet in Microsoft Office 2010 software.

Results: Most of them were aware of the term pharmacovigilance (PV) (95.45\%). $54.55 \%$ agreed to be trained on how to report an ADR. $88.63 \%$ knew about the existence of pharmacovigilance committee in the institute. $93 \%$ of participants knew that Central Drug Standard Control Organization (CDSCO) is responsible for monitoring of ADRs. 56.82\% were aware about VIGIBASE an online software to report ADR. 81.82\% of participants had agreed to witness ADRs in patients but only $38.64 \%$ reported them. The main reason behind it was non availability of ADR forms. $42.55 \%$ opine that mobile based app would be the most preferred method to send ADR information to an ADR reporting center.

Conclusions: There exists a huge gap between ADR experienced and ADR reported by PG students. Participants agreed upon necessity of reporting ADR and periodic briefing about PV.
\end{abstract}

Keywords: Attitude, Adverse drug reaction, Knowledge, Practice, Post graduate students, Pharmacovigilance

\section{INTRODUCTION}

An adverse drug reaction (ADR) is defined by WHO as "a response to a drug which is noxious and unintended, and which occurs at doses normally used in man for the prophylaxis, diagnosis or therapy of disease or for the modification of physiological function." Pharmacovigilance is the science and activities which are related to the detection, assessment, understanding and the prevention of adverse effects or any other drug related problems. ${ }^{1}$
ADRs are a major cause of morbidity and mortality and add cost to the treatment. ${ }^{2}$

National Pharmacovigilance Program (NPP) was launched by Ministry of Health and Family Welfare (MHFW), Government of India (GOI) in 2010. There are zonal, regional, peripheral pharmacovigilance (PV centers).

ADR monitoring helps to detect new, serious and even unknown reactions. Reporting of known ADRs helps to establish the frequency of occurrence and identifies risk 
factors which may be predictable. By adding onto the existing database, it helps in signal detection. This enables regulatory agencies to formulate drug use guidelines, issue warnings or even ban/withdraw the drug from the market. ${ }^{2}$

Only 6-10\% of all ADRs are reported. ${ }^{3}$ The success of a pharmacovigilance program depends upon the involvement of the healthcare professionals and voluntary reporting the ADRs. Being the key healthcare providers, doctors, nurses and pharmacists have immense responsibility in identifying and reporting $\mathrm{ADR}$ and strengthening the pharmacovigilance program by filling an ADR form of CDSCO.

Under-reporting of adverse drug reactions (ADRs) by healthcare professionals is a common problem. ${ }^{4,5}$

Hence, to improve the reporting rate this study was planned to evaluate the baseline Knowledge, attitude, and practice (KAP) of post-graduate (PG) students at tertiary care teaching hospital.

The aim was to assess the KAP regarding ADR reporting among PG students of the tertiary care teaching hospital at Talegaon (Dabhade), Pune, Maharashtra, India.

The objectives were to assess the causation of underreporting of ADRs if exists, to compare the findings of this study with the results of published studies from India on KAP of ADR reporting among postgraduate students and to recommend the measures to improve spontaneous ADR reporting.

\section{METHODS}

This was a cross sectional, observational, noninterventional questionnaire-based study. The study was conducted among post graduate students of various clinical departments at Bhausaheb Sardesai Rural Hospital, Talegaon, Pune, Maharashtra, India.

ADR reporting program exists in our institution since 2014. The approval for conducting the study was obtained from Institutional Ethics Committee (IEC) of the college.

The study was conducted over a period of six months from April 2018 to September 2018.

\section{Study population}

Postgraduate students of all $\left(1^{\text {st }}, 2^{\text {nd }}, 3^{\text {rd }}\right)$ years pursuing post-graduation in various clinical subjects were enrolled in the study, total number $(n)=44$.

\section{Inclusion criteria}

Postgraduate students of all $\left(1^{\text {st }}, 2^{\text {nd }}, 3^{\text {rd }}\right)$ years pursuing post-graduation in various clinical subjects were enrolled in the study.

\section{Exclusion criteria}

Those who were not willing to participate.

\section{Procedure}

A KAP questionnaire was designed using the precedence set by similar studies. ${ }^{3,6-8}$

\section{Study instrument}

A predesigned KAP questionnaire based on earlier studies for assessing KAP of ADR reporting.

\section{Study conduct}

A total of 49 questions- 21 to evaluate the knowledge, 13 to know the attitude of doctors, 15 questions to assess the practice pattern towards ADR reporting. They were asked about drawbacks in current system of ADR reporting in our institute and remarks/suggestions, if any and possible ways to improve ADR reporting.

All the study participants were contacted in person by the principal investigator at their respective departmental Outpatient Department (OPD).

Information sheet regarding objective and rational of present study was given to the PG students. The participants were personally briefed about the instructions for filling the questionnaire. Any doubts about the filling of the questionnaire were clarified by the principal investigator.

The respondents were allowed to strike multiple options wherever applicable. A duly signed written informed consent was obtained. To enhance the response rate, the doctors were requested to complete the questionnaire and hand it back in 30 mins. They were not allowed to consult anyone during that time.

Anonymity with regards to their names was ensured. The returned questionnaire was checked for the completeness of data.

The KAP survey questionnaire was analyzed questionwise and their percentage value were calculated using Microsoft Excel spread sheet in MS Office 2010 software.

\section{RESULTS}

The questionnaire was distributed to 45 prescribers out of which 44 PG students returned the completed questionnaire.

An average time required to fill the questionnaire was 1315 minutes.

The response rate among the resident doctors was $97.77 \%$. 
Table 1: Knowledge of PG students towards ADR reporting ( $n=44)$.

\begin{tabular}{|c|c|c|c|c|c|}
\hline Sr. no. & Question & Yes $(\%)$ & No $(\%)$ & Don't know (\%) & Maybe (\%) \\
\hline 1 & Do you know the term 'Pharmacovigilance'? & 95.45 & 4.55 & & \\
\hline 2 & $\begin{array}{l}\text { Have you anytime read any article on prevention of } \\
\text { adverse drug reactions }\end{array}$ & 40.9 & 36.36 & 13.63 & 9.09 \\
\hline 3 & $\begin{array}{l}\text { Have you ever been trained on how to report } \\
\text { Adverse Drug Reaction (ADR) }\end{array}$ & 54.55 & 45.45 & & \\
\hline 4 & $\begin{array}{l}\text { Is there any pharmacovigilance committee in your } \\
\text { Institute }\end{array}$ & 88.63 & 4.55 & 6.82 & \\
\hline 5 & $\begin{array}{l}\text { Do you think that there should be DR reporting } \\
\text { centre in OPD complex of the hospital? }\end{array}$ & 86.36 & 13.64 & & \\
\hline 6 & $\begin{array}{l}\text { Should the adverse reactions due to blood } \\
\text { transfusion be reported? }\end{array}$ & 86.36 & 13.64 & & \\
\hline 7 & Should the reactions due to vaccination be reported? & 93.18 & 6.82 & & \\
\hline 8 & Is ADR synonymous to adverse event? & 52.27 & 47.73 & & \\
\hline 9 & $\begin{array}{l}\text { Are you aware about the visit of any staff member } \\
\text { of Pharmacology department to your department } \\
\text { regarding ADR reporting? }\end{array}$ & 70.45 & 29.55 & & \\
\hline 10 & $\begin{array}{l}\text { Is the entire ADR profile known before any drug is } \\
\text { marketed? }\end{array}$ & 34.1 & 65.9 & & \\
\hline 11 & $\begin{array}{l}\text { Do you think frequent awareness programs are } \\
\text { needed to update yourself regarding ADR } \\
\text { knowledge? }\end{array}$ & 81.82 & 18.18 & & \\
\hline 12 & $\begin{array}{l}\text { Are you aware of the pharmacovigilance program } \\
\text { of India? }\end{array}$ & 47.73 & 52.27 & & \\
\hline
\end{tabular}

The above table describes about the knowledge of PG students towards ADR reporting and the percentage of their responses in "Yes" or "No" (Table 1).

About $95.45 \%$ of the resident doctors were aware about the term pharmacovigilance (PV) and $93.18 \%$ of participants knew that PV deals with ADRs (Table 1). 56.82\% of participants were aware about that medical practitioners, pharmacist, nurses, patients/health workers all can report ADR (Table 1).

About $88 \%$ of participants knew that PV committee exists in the institute. $54.55 \%$ agreed to be trained on how to report an ADR. $41 \%$ of participants were aware that an ADR form is to be sent to the pharmacology department. $45.45 \%$ of participants suggested that there should PV briefing every 6 months. $88.36 \%$ answered that there should be an ADR reporting center in OPD (Table 1).

About $72.73 \%$ of participants opined that an ADR monitoring center should be every hospital.

About $93 \%$ of participants knew that CDSCO is the regulatory body responsible for monitoring of ADRs. $56.82 \%$ of participants knew that VIGIBASE, is the "WHO online database" for reporting ADR. 40.9\% have read an article on ADR (Table 1).

About $61.36 \%$ opined that 2 to $21 \%$ of patients require hospitalization due to ADRs (Table 1). $79.35 \%$ of participants said that $10 \%$ of in-patients experience ADRs. $79.59 \%$ of participants have reported skin rash as the most common ADR.

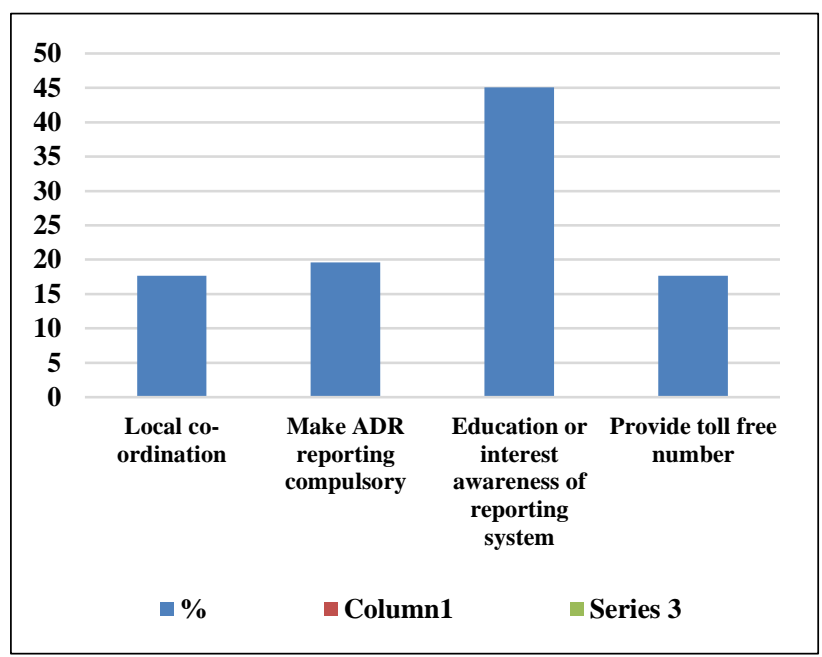

Figure 1: Methods to improve ADR reporting.

"Education or interest awareness of reporting system" is the most preferred method to improve ADR reporting (Figure 1).

Table 2 describes about the attitude of PG students towards ADR reporting and percentage of their responses in "Yes" or "No" (Table 2). 
Table 2: PG student's attitude toward ADR reporting $(n=44)$.

\begin{tabular}{|c|c|c|c|c|}
\hline Sr. no. & Question & Yes $(\%)$ & No $(\%)$ & Don't know (\%) May be (\%) \\
\hline 1 & $\begin{array}{l}\text { Do you ADR reporting is a professional obligation } \\
\text { or mandatory for you? }\end{array}$ & 75 & 6.82 & 18.18 \\
\hline 2 & $\begin{array}{l}\text { Do you think ADR reporting will improve patient's } \\
\text { safety? }\end{array}$ & 93.18 & 2.27 & 4.55 \\
\hline 3 & $\begin{array}{l}\text { Do you think pharmacovigilance should be taught } \\
\text { in detail to healthcare professionals? }\end{array}$ & 95.45 & 4.55 & \\
\hline 4 & $\begin{array}{l}\text { Have you attended the lecture on } \\
\text { Pharmacovigilance held in our institute? }\end{array}$ & 61.36 & 22.73 & 15.91 \\
\hline 5 & $\begin{array}{l}\text { Do you agree whether one should be certain of the } \\
\text { causality of ADR? }\end{array}$ & 88.64 & 11.36 & \\
\hline 6 & $\begin{array}{l}\text { Do you agree whether ADR reporting by one } \\
\text { person can make a significant difference to the } \\
\text { community? }\end{array}$ & 86.36 & 13.64 & \\
\hline 7 & $\begin{array}{l}\text { Do you agree whether ADR reporting in the } \\
\text { hospital should be financially rewarded? }\end{array}$ & 52.28 & 47.72 & \\
\hline 8 & $\begin{array}{l}\text { Is the ADR reporting and monitoring system in } \\
\text { your hospital, useful for your practice? }\end{array}$ & 75 & 25 & \\
\hline 9 & $\begin{array}{l}\text { Do you think that a clinical pharmacist's assistance } \\
\text { in detection, reporting and management of adverse } \\
\text { drug reaction could be useful? }\end{array}$ & 88.64 & 11.36 & \\
\hline
\end{tabular}

Table 3: Practice of PG students towards ADRs $(n=44)$.

\begin{tabular}{|c|c|c|c|c|c|}
\hline Sr. no. & Question & Yes $(\%)$ & $\mathrm{No}(\%)$ & Don't know (\%) & May be (\%) \\
\hline 1 & $\begin{array}{l}\text { Have you ever experienced adverse drug reactions } \\
\text { in your patient during your professional practice? }\end{array}$ & 81.82 & 18.18 & & \\
\hline 2 & Have you ever seen ADR reporting form? & 77.28 & 22.72 & & \\
\hline 3 & Are the ADR forms available in IPD, OPD? & 63.64 & 15.9 & & 20.45 \\
\hline 4 & Have you ever reported an ADR? & 38.64 & 61.36 & & \\
\hline 5 & Do you find any difficulty in reporting? & 36.36 & 63.64 & & \\
\hline 6 & $\begin{array}{l}\text { Is there a need of sending the drug sample } \\
\text { responsible for ADR with the form? }\end{array}$ & 36.36 & 63.64 & & \\
\hline
\end{tabular}

Professional apathy, scarcity of trained personnel, lack of reporting culture and inadequate communication: all are considered as challenges to implement PvPI (Figure 2).

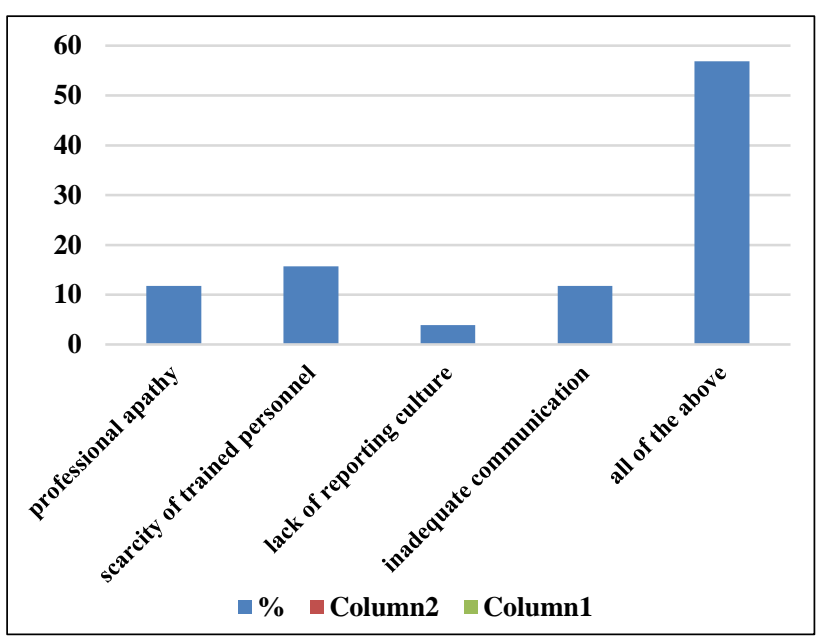

Figure 2: Challenges for implementing PvPI.
Table 3 describes about the practice of PG students towards ADR reporting and the percentage of their responses in "Yes" or "No" (Table 3).

Total $45.45 \%$ of participants have not reported any ADR. $43 \%$ of participants have reported about 0-5 ADRs per month.

Total $36.36 \%$ participants faced difficulties in reporting ADRs.

Non availability of ADR forms is the most common difficulty faced while reporting ADRs (Figure 3).

About 93.18 ticked all cases of ADRs should be reported, but some of them $(4.45 \%)$ were in the opinion of reporting serious and life threatening ADRs. $36.06 \%$ of participants said that seriousness of ADR is the most important factor while deciding to report an ADR. 36\% of participants include $\mathrm{ADR}$ as a differential diagnosis 0-5 times per month (Table 3). 


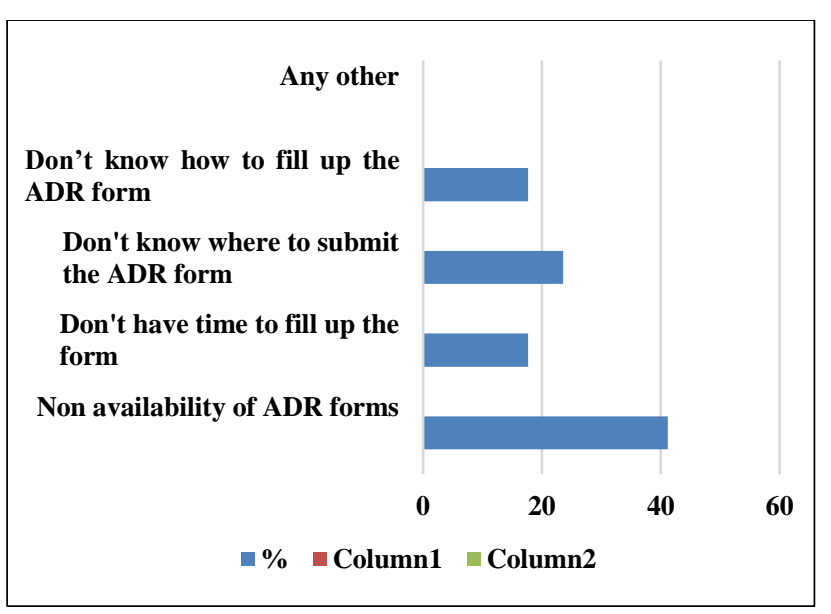

Figure 3: Difficulties in reporting ADR.

About $30 \%$ of participants knew that a serious ADR to be reported to the regulatory body within 24 hours.

About $42.55 \%$ suggested that mobile based app reporting will the most preferred method to send ADR information to an ADR reporting center. $29.33 \%$ participants gathered information regarding ADR from textbooks as well as internet (Table 3).

\section{DISCUSSION}

The present study was a questionnaire-based study that included 44 post graduate students of a tertiary care teaching hospital. The filled questionnaire was returned and analyzed.

The response rate of the completed questionnaires was $97.77 \%$ (Table 1) which was more than other study carried amongst doctors in Amaravati (64.95\%) and 77.2\% in a study carried out in PG students of two government medical colleges by Gupta P et al. ${ }^{9,10}$ This may be because as the present study included only PG students which were easily accessible and number of participants were less.

Majority of the PG students were familiar with the term PV (95.45\%) and most of them knew that PV deals with ADRs $(93.18 \%)$ (Table 1) as par with findings of the study done in doctors by Siddheshwara et al, (86.36\%)- but different from a study done in clinicians and PG students of medical college in Amravati (57.75\%). ${ }^{9,11}$

Majority knew about Central Drugs Standard Control Organization (CDSCO) is the regulatory body responsible for monitoring ADR (93.18\%) (Table 1) similar to the result seen in a study done in health care professionals in teaching hospital in South India (78.2\%) and about Vigibase, online database for ADR reporting which a good sign contradictory with study done in clinicians and PG students by Dudhe et al, (43\%) and in PG students of tertiary care hospital in Gujarat, India $(39.6 \%))^{3,9,12}$ Majority of the participants $(70.45 \%)$ (Table 1), were aware that there exists a PV committee in Bhausaheb
Sardesai Rural Hospital, Talegaon, Pune, Maharashtra, India and visit by a staff member of Pharmacology department every week to remind about ADR reporting, an initiative taken by the department to improve ADR reporting in which is in accordance with the study done by Gupta et al, in healthcare professionals (71.3\%) and doctors were aware of the ADR monitoring center (AMC) in the institute in a study done by Khan et al, $(80.9 \%) .{ }^{9,13}$ Majority of PG students $(86.36 \%)$ were aware that ADR due to blood transfusion and vaccination $(93.18 \%$ ) (Table 1) should be reported as seen in a study done among prescribers by Desai CK et al $(20.6 \%){ }^{6}$

Half of the PG students $(56.82 \%)$ opined that medical practitioners, pharmacist, nurses, patients/health workers all are responsible for reporting ADR (Table 1) similar to study done by Radhakrishna $\mathrm{R}$ et al, $(85 \%) .{ }^{14}$ Clinical pharmacist assistance could be beneficial to them as stated by the PG students. This is a welcome sign of ADR reporting. This result is in accordance with the study done among doctors by Dudhe et al, (75\%). ${ }^{9}$ In a study done among PG students by Gupta et al, in Maharashtra state, respondents did not identify nurses, pharmacist as qualified reporters. ${ }^{10}$ Active involvement of paramedical staff in spontaneous reporting of ADR would increase ADR reporting.

There is positive attitude of PGs towards ADR reporting, as they opined that ADR reporting was a professional obligation (75\%) (Table 2) similar to study done among doctors by Gupta et al, $(80.9 \%), 90 \%$ by Kunoor et al. ${ }^{9,10}$ Radhakrishnan et al, has also stated same finding in a study done in physicians and postgraduates in tertiary health center in Karnataka, India. ${ }^{14}$ ADR reporting as a professional obligation will have moral binding to healthcare professionals and ethical issues.

A study done by Pimplekhute et al, states only $15.19 \%$ residents said that ADR reporting should be compulsory. ${ }^{15}$ $86.36 \%$ of participants of the present study stated that reporting by one person can make a significant difference to community (Table 2 ) different from study done by Khan et al, $(16.2 \%)$, similar to study done in clinicians in by Kunnoor et al $(83 \%){ }^{8,13}$

Most of the post graduate students suggested that there should be an ADR reporting center in the OPD complex of the hospital $(86.36 \%)$ in a study done among prescribers by Radhakrishna et al, and ADR monitoring center should be in every hospital. ${ }^{14}$ This is in accordance with study done in nurses by Radhakrishna et al, and Gupta et al, in South India (74.3\%). ${ }^{12,14}$ Frequent awareness programs are needed to update the knowledge about ADRs and should be taught in detail to healthcare professionals. Rehan HS has documented educational intervention have been found to update the knowledge and greater degree of awareness. ${ }^{5}$ $\mathrm{He}$ also stated that doctor needs reinforcement regarding ADR reporting. Most of the participants were unaware of difference between ADR and Adverse event, so their concept about it to be addressed. 
About 52.28\% participants opined that the use of financial incentives, as a tool to stimulate reporting (Table 2) similar to the study done by Gupta et al, $(73.6 \%)$ contradictory with the study conducted by Dudhe et al. ${ }^{9,10}$ It can cause over reporting by health professionals to obtain financial reward.

About $75 \%$ of PG students opined that ADR reporting and monitoring system in the institute was helpful to them which shows a positive attitude of them towards ADR reporting (Table 2 ).

Skin rash was the most the common ADR reported by them (79.59\%) (Table 2) similar to the study done by Desai et al, in which common ADR reported was cutaneous $(35.7 \%)$ followed by GIT (27.7\%). ${ }^{6}$

PG students stated that the most important reason to report an ADR was to improve patient safety and second important reason, to identify new ADRs as also seen in the study done among doctors by Desai et al, Dudhe et al and also seen in a study done in PG students in Gujarat-where the percentage was $28.8 \%$ and $24.6 \%$ respectively. ${ }^{3,6,9}$

Furthermore, 56.86\% agreed that professional apathy, scarcity of trained personnel, lack of reporting culture and inadequate communication are the most challenges in implementing PvPI (Figure 2) which were also reported in a study done by Upadhyaya et al. ${ }^{3}$

Most respondents in the study obtained the information regarding ADRs from textbook and internet (Table 3). However, a study done in Amaravati it was obtained from drug information sheets, texts on drugs. ${ }^{3}$ Interestingly, majority of doctors $(81.82 \%)$ have noticed ADR, but less than half of them have reported it which was also seen in the study done among doctors by Dudhe et al $(60 \%)$ and Gupta et al (22.6\%) and Kunnoor et al-24\%.8-10

So, it was observed that right attitude for ADR reporting existed among PGs in the present study but actual practice of ADR reporting was lacking similar to the study done in PG students in Gujarat and South India. ${ }^{3,12}$ Lack of training for clinical doctors, on how to diagnose and report ADRs could be the probable reason for under reporting.

According to participants mobile app would be a preferred method as to make reporting easy and convenient. It may improve quantum and quality of reports. The difficulties and factors that discourage them from reporting were nonavailability of ADR forms (40\%), difficulty in filling ADR form (20\%), lack of time (18\%) and difficulty in diagnosing an ADR (18\%) (Table 4).

A study done in PG students in tertiary care hospital Gujarat had similar findings as participants did not know how to report (44.55\%), where to report (47.52 ). ${ }^{3}$ A study done among doctors by Desai et al, stated lack of access to ADR reporting form (49.2\%) was major factor for discouraged reporting. 6
Table 4: Factors that discourage prescribers from reporting ADRs.

\begin{tabular}{|ll|}
\hline Factors & Frequency (\%) \\
\hline Did not know how to report ADR & $20(18.02)$ \\
\hline Legal liability issues & $8(7.21)$ \\
\hline $\begin{array}{l}\text { Lack of time to report ADR/ Lack } \\
\text { of time to actually look for an ADR } \\
\text { and fill in a report }\end{array}$ & $18(16.22)$ \\
\hline $\begin{array}{l}\text { Ambition to publish case reports } \\
\text { personally }\end{array}$ & $3(2.7)$ \\
\hline Other colleagues are not reporting & $6(5.41)$ \\
\hline Concern that report may be wrong & $9(8.11)$ \\
\hline Not knowing where to report & $16(14.41)$ \\
\hline $\begin{array}{l}\text { Lack of access to ADR reporting } \\
\text { form }\end{array}$ & $11(9.91)$ \\
\hline $\begin{array}{l}\text { Difficult to decide whether ADR } \\
\text { has occurred or not }\end{array}$ & $18(16.22)$ \\
\hline Other (please specify) & $2(1.8)$ \\
\hline
\end{tabular}

About 36\% participants declared that they include ADR as differential diagnosis in contrast to study done by Kunoor et al, $(57 \%)$ (Table 3$){ }^{8}$

According to participants ADR reporting can be improved by local co-ordination, as also reported by study done among health care professionals by Siddeshwara et al. ${ }^{11}$

To address these difficulties, factors which discourage them, ADR reporting guidelines should be made available in form of booklets, posters at conspicuous locations in hospital. Interventions are needed to generate awareness on how, what, where to report an ADR. Steps to be taken to make the forms easily available in OPD and in wards and making ADR reporting compulsory.

Therefore, increasing awareness about pharmacovigilance program and AMC through personal communication and advertisement appears necessary to enhance reporting.

The fact that majority of respondents agreed that reporting of ADR is necessary, and pharmacovigilance should be taught in detail to healthcare professionals was major findings from this study.

\section{CONCLUSION}

Majority of PG students have good knowledge and attitude, understand the need for reporting but lack of practice towards ADRs as the reporting rate of ADRs by them was very low. This study can give insight into possible interventions that could be planned in future. ADR reporting can be improved by increasing awareness about importance of reporting, reporting system and obligation to report. ADR center in OPD and repeated PV briefing will help in increasing ADR reporting. With ADR reporting system in place at the institution, the suggestions are to be implemented to strengthen ADR reporting system with easy accessibility to ADR forms. Gestures like 
acknowledgement of receipt of report and an appreciation note could also help motivating them to continue the PV activity.

It is a very basic study to identify KAP of PGs. The present study has certain limitation as number of PG students were less. Other health professionals like doctors working in the institute, nurses, pharmacist who are continuously in touch with patients are not included in the study. The study findings cannot be applied to wider medical community as the study is restricted to only PG students practicing in a hospital setup where already a formal ADR reporting system exist.

\section{RECOMMENDATION}

Sensitization workshops on PV and ADR to all the PG students at least twice in a year.

\section{ACKNOWLEDGEMENTS}

Authors would like to thank all PGs for the participation during study.

Funding: No funding sources

Conflict of interest: None declared

Ethical approval: The study was approved by the Institutional Ethics Committee

\section{REFERENCES}

1. KD Tripathi. Essentials of Medical Pharmacology. 8th Ed. 2018; 92-101.

2. Shivarudraiah PR, Kudthni RH, Santosh R. An evaluation of knowledge, attitude and practices of pharmacovigilance among prescribers in teaching hospital of south India. Int J Basic Clin Pharmacol. 2003;6:11.

3. Upadhyaya HB, Vora MB, Nagar JG, Patel PB. Knowledge, attitude and practices toward pharmacovigilance and adverse drug reactions in postgraduate students of Tertiary Care Hospital in Gujarat Adv Pharm Technol Res. 2015;6(1):29-34.

4. Arulmani R, Rajendran SD, Suresh B. Adverse drug reaction monitoring in a secondary care hospital in South India. Br J Clin Pharmacol. 2007;65:210-6.

5. Rehan HS, Vasudev K, Tripathi CD. Adverse drug reaction monitoring: knowledge, attitude and practices of medical students and prescribers. Natl Med J India. 2002;15:24-6.

6. Desai CK, Iyer G, Panchal J, Shah S, Dikshit RK. An evaluation of knowledge, attitude, and practice of adverse drug reporting among prescribers at a tertiary care hospital. Perspect Clin Res. 2011;2(4):129-36.

7. Lohit K, Vidya KR, Manjunath GN. Development and validation of questionnaire to assess the knowledge, attitude and practice towards adverse drug reactions reporting among healthcare professionals. J Int Med Dentistry. 2016;3(2):63-72.

8. Kunnoor NS, Lohit SK. Perception of doctors towards Adverse Drug Reaction (ADR) reporting: a cross sectional survey using a validated questionnaire. Int $\mathrm{J}$ Basic Clin Pharmacol. 2017;6(11):2671-5.

9. Dudhe BG, Bhore AS. Knowledge, Attitude and Practices of clinician regarding reporting of Adverse Drug reaction (ADR) in Dr. Punjabrao Deshmukh Memorial Medical College, Amravati. World J Pharmaceut Sci World J Pharma Sci. 2014;6(2):62-9.

10. Gupta P, Udupa A. Adverse drug reaction reporting and pharmacovigilance: knowledge, attitude and perceptions amongst resident doctors. J Pharm Sc Res. 2011;3(2):1064-9.

11. Siddheshwara MG, Kumar JS, Vardhamane SH. Knowledge, attitude and practice of adverse drug reactions reporting among healthcare professionals. IJPR. 2016;6(1).

12. Gupta SK, Nayak RP, Shivaranjani R, Vidyarthi SK. A questionnaire study on the knowledge, attitude, and the practice of pharmacovigilance among the healthcare professionals in a teaching hospital in South India. Persp Clin Res. 2015;6(1):45.

13. Khan SA, Goyal C, Chandel NBS, Rafi M. Knowledge, attitude and practices of doctors to adverse drug reaction reporting in a teaching hospital in India. 2013;4:191-6.

14. Radhakrishnan R, Vidyasagar S, Varma DM. An educational intervention to assess knowledge attitude practice of pharmacovigilance among Health care professionals in an Indian tertiary care teaching hospital. Int J Pharm Tech Res. 2011;3:678-92.

15. Pimpalkhute SA, Jaiswal KM, Sontakke SD, Bajait CS, Gaikwad. Evaluation of awareness about Pharmacovigilance and adverse drug reaction monitoring among resident doctors of a tertiary care teaching hospital. Ind J Med Sci. 2012;66(3-4):55-61.

Cite this article as: Chincholkar AS, Naik A.

Knowledge, attitude and practice towards adverse drug reactions reporting in post graduate students of a tertiary care hospital. Int J Basic Clin Pharmacol 2019;8:1320-6. 